\title{
Antibacterial silver-doped phosphate-based glasses prepared by coacervation
}

Benjamin A. Kyffin, ${ }^{a}$ Farzad Foroutan, ${ }^{a}$ Farah N. S. Raja, ${ }^{\text {b }}$ Richard A. Martin, ${ }^{\text {b }}$ David M. Pickup, ${ }^{c}$ Spencer E. Taylor, ${ }^{a}$ Daniela Carta ${ }^{\mathrm{a}, *}$

${ }^{a}$ Department of Chemistry, University of Surrey, GU2 7XH, Guildford, UK.

${ }^{b}$ School of Engineering \& Applied Science and Aston Institute for Materials Research, Aston University, Aston Triangle, Birmingham, B4 7ET, UK.

'School of Physical Sciences, Ingram Building, University of Kent, Canterbury, Kent, CT2 7NH, UK.

*Corresponding author: Dr D. Carta, Department of Chemistry, University of Surrey, GU2 7XH, Guildford, UK. Email:d.carta@surrey.ac.uk

\section{Abstract}

Phosphate-based glasses are materials of great interest for the regeneration and repair of damaged hard or soft tissues. They have the desirable property of slowly dissolving in the physiological environment, eventually being totally replaced by regenerated tissue. Being bioresorbable, they can simultaneously induce tissue regeneration and deliver therapeutic agents (e.g. antibacterial ions) in a controlled way. In this work, we have synthesised a series of glasses in the $\mathrm{P}_{2} \mathrm{O}_{5}-\mathrm{CaO}-\mathrm{Na}_{2} \mathrm{O}$ system doped with $\mathrm{Ag}_{2} \mathrm{O}$ using the coacervation method. The addition of silver is known to provide the glass with antibacterial properties due to the release of $\mathrm{Ag}^{+}$ions into the body fluid. The coacervation method is a facile, water-based technique which offers significant advantages over the conventional meltquench route for preparing phosphate-based glasses which requires melting of metal oxide powders at high temperatures $\left(1000-1200{ }^{\circ} \mathrm{C}\right)$. The properties of the initial colloidal polyphosphate systems (coacervates) as a function of the $\mathrm{Ag}_{2} \mathrm{O}$ content were characterised using rheology and liquid state ${ }^{31} \mathrm{P}$ NMR. The effect of $\mathrm{Ag}^{+}$addition on the final dried glasses was investigated using thermal analysis, Raman spectroscopy and X-ray diffraction. The antibacterial activity was assessed against Staphylococcus aureus (S. aureus), a bacterial strain commonly found in post-surgery infections. A dose-dependent antimicrobial effect was seen with an increasing silver content. 


\section{Introduction}

Glass materials that can induce healing of damaged tissues have received increased interest in biomedical research. ${ }^{1}$ In particular, silicate-based glasses have shown great potential in the regeneration of hard tissues, such as bone, ${ }^{2-4}$ and as soft tissues, like cartilage. ${ }^{5}$ However, due to their poor solubility, silicate-based glasses are generally used to manufacture long-term implants. As a result, there are concerns over their effects in-vivo as they could be susceptible to long-term failure and inflammatory reactions. ${ }^{6}$

Phosphate-based glasses (PBGs) have recently been presented as a promising new generation of multifunctional biomaterials that can simultaneously induce tissue healing and controlled release of therapeutic molecules. PBGs are bioresorbable, as they react and dissolve in the physiological environment and are eventually totally replaced by regenerated hard or soft tissue. ${ }^{7}$ Currently, the most common bioresorbable materials used in biomedical research are polymers (e.g. polylactic and polyglycolic acids). However, their degradation often results in crystalline fragments with heterogeneous chain-lengths that could lead to inflammation at the implantation site. ${ }^{8}$ In contrast to polymer-based bioresorbable systems, PBGs leave no crystalline product that could lead to inflammation and unlike silicate-based glasses, phosphate-based systems are completely soluble in body fluids. Solubility and ion release of PBGs can be controlled and tailored according to the desired application by altering the glass composition. ${ }^{9}$ This makes them ideal materials for drug delivery applications, ${ }^{10}$ and the delivery of biologically active molecules (e.g. growth factors) or antibacterial ions such as copper, ${ }^{11}$ and silver. ${ }^{12}$

To date, the conventional technique used to prepare PBGs is the melt-quench (MQ) process that requires the melting of oxide powders at high temperatures $\left(1000-1200{ }^{\circ} \mathrm{C}\right) \cdot{ }^{13}$ However, this method often leads to non-homogeneous, bulk glasses that cannot be used for hosting temperaturesensitive molecules and can lead to reduction of antibacterial ions. Composition is also difficult to control because of the loss of volatile phosphate species during heating. The sol-gel route (SG) is often used as an alternative technique for the synthesis of PBGs. ${ }^{14-18}$ However, phosphorus precursors (typically alkoxides) used in the sol-gel process are air-sensitive and need to be dissolved in organic solvents. Moreover, gelation times can be lengthy. The use of coacervation, however, provides an attractive alternative to the above methods, as it is a rapid, room temperature, waterbased, technique. Moreover, coacervates can be hydrolysed into simple, non-toxic products (e.g. phosphate salts). ${ }^{19}$ The method is based on the formation of a colloidal polyphosphate system 
(coacervate) by the slow addition of $\mathrm{M}^{2+}$ ions, $\left(\mathrm{M}=\mathrm{Ca}^{2+}, \mathrm{Co}^{2+}\right.$ and $\left.\mathrm{Ni}^{2+}\right)$ to an aqueous sodium polyphosphate solution. ${ }^{20-23}$ The formation of a coacervate is an electrostatically-driven process; the electrostatic association between the $\mathrm{M}^{2+}$ ions and charged oxygen species in the system lowers the effective dielectric constant below that of water, resulting in phase separation. ${ }^{24,25}$ By altering the type and content of ions added to the system the dielectric constant can be changed and this results in an alteration of the viscosity of the coacervate. ${ }^{24}$ The wet viscous coacervate can be used as formed, or dried to remove the excess of water in order to obtain a dry glass. The majority of studies presented so far in the literature refer to the as-made polyphosphate coacervates, with reference to the processes behind their formation, ${ }^{26,27}$ rheology, ${ }^{22,28}$ structure, ${ }^{20,23,24,29-31}$ effect of thermal treatment, ${ }^{32}$ degradation and haemostatic properties. ${ }^{19}$

However, very little work has been presented on dried PBG prepared using the coacervate method and particularly on the relationship between the as-made coacervate and the final glass. Only a handful of coacervate-derived dried phosphate systems have been presented to date and include $\mathrm{P}_{2} \mathrm{O}_{5}-\mathrm{ZnO}-\mathrm{Na}_{2} \mathrm{O}$ glasses, ${ }^{33,34}$ and $\mathrm{P}_{2} \mathrm{O}_{5}-\mathrm{NiO}-\mathrm{Na}_{2} \mathrm{O}$ glass-ceramics. ${ }^{21}$ Only very recently, Pickup et al. ${ }^{23}$ presented coacervate-based $\mathrm{P}_{2} \mathrm{O}_{5}-\mathrm{CaO}-\mathrm{Na}_{2} \mathrm{O}$ systems as potential biomedical materials. Ternary glasses in the $\mathrm{P}_{2} \mathrm{O}_{5}-\mathrm{CaO}-\mathrm{Na}_{2} \mathrm{O}$ system prepared either using the $\mathrm{MQ}$ and to a lesser extent the SG techniques have been shown to be ideal bioresorbable materials for applications such as dental repair, orthopaedic implants. ${ }^{35,36}$ In particular, addition of silver to MQ glasses has been shown to infer the glasses with antibacterial activity being the silver ions slowly released by PBGs during dissolution. ${ }^{37,38}$ However, no systematic work has been presented to date on the effect of silver addition to PBG prepared by coacervation. Specifically, little work has been presented on the rheology of polyphosphate coacervates and the structure of phosphate chains, ${ }^{28}$ especially as applied to silver-doped coacervates.

Thus, herein we present a structural and antibacterial study of quaternary glasses prepared using the coacervation method in the $\mathrm{P}_{2} \mathrm{O}_{5}-\mathrm{CaO}-\mathrm{Na}_{2} \mathrm{O}-\mathrm{Ag}_{2} \mathrm{O}$ system with $\mathrm{Ag}_{2} \mathrm{O}$ contents of $1,3,5,9$ and $14 \mathrm{~mol} \%$. A ternary system without addition of $\mathrm{Ag}_{2} \mathrm{O}$ was also prepared for comparison. Rheological measurements and liquid ${ }^{31}$ P NMR spectroscopic analysis were conducted on the asmade coacervates whereas structural characterisation and antibacterial studies against $S$. aureus were performed on the dried glasses. The effects of calcination temperature on the structure of the glasses were also investigated. 


\section{Experimental}

\subsection{Synthesis}

The synthesis of polyphosphate coacervates was adapted from Pickup et al. ${ }^{23} \mathrm{~A} 4 \mathrm{M}$ aqueous solution of sodium polyphosphate $\left(\left(\mathrm{NaPO}_{3}\right)_{\mathrm{n}}\right.$; Merck, 99.0\%) was slowly added to an equal volume of a $2 \mathrm{M}$ aqueous solution of calcium nitrate tetrahydrate $\left(\mathrm{Ca}\left(\mathrm{NO}_{3}\right)_{2} \cdot 4 \mathrm{H}_{2} \mathrm{O} ;\right.$ Acros, $\left.99.0 \%\right)$ using a syringe pump $\left(0.3 \mathrm{~mL} \cdot \mathrm{min}^{-1}\right)$ with vigorous stirring. During addition, phase separation occurred in which an upper aqueous layer and a lower coacervate layer formed. After addition was complete, the mixture was stirred for one hour and then allowed to settle for a further hour. The aqueous layer was removed using a pipette and the opaque coacervate bottom layer was left to settle for a further 24 hours. After this time any remaining supernatant solution was removed leaving only the settled transparent coacervate. The coacervate was dried in a vacuum desiccator at room temperature for 48 hours in which time it solidified. The dried coacervate was then further calcined at $300{ }^{\circ} \mathrm{C}$ or 400 ${ }^{\circ} \mathrm{C}$ with a heating rate of $1{ }^{\circ} \mathrm{C} \cdot \mathrm{min}^{-1}$. For the production of silver-doped glasses, a $2 \mathrm{M}$ aqueous solution of silver nitrate $\left(\mathrm{AgNO}_{3}\right.$; Alfa Aesar, $\left.99.9 \%\right)$ was added with vigorous stirring following the complete addition of calcium nitrate, after which the mixtures were allowed to settle. The volume of silver nitrate solution used was dependent on the desired mol\% $\mathrm{Ag}_{2} \mathrm{O}$ in the final glass composition.

\subsection{Characterisation}

Liquid state ${ }^{31} \mathrm{P}$ nuclear magnetic resonance spectroscopy ( ${ }^{31} \mathrm{P} N \mathrm{NM}$ ) was performed using a Bruker Avance III $500 \mathrm{MHz}$ spectrometer taking 256 scans. The sodium polyphosphate was dissolved in water and $\mathrm{D}_{2} \mathrm{O}$ added to allow for signal locking. The coacervates were dissolved in a $200 \mathrm{mM}$ aqueous ethylenediaminetetraacetic acid disodium salt (EDTA) solution at $\mathrm{pH} 10$. Spectra were analysed using Mestre Nova software and referenced to orthophosphoric acid.

Rheology was performed on the liquid coacervates after a settling period of 24 hours. The measurements were performed using a TA Instruments Discovery HR-2 hybrid rheometer with a 40 $\mathrm{mm}$ diameter, $2^{\circ}$ angle cone and plate arrangement. Steady shear tests (rotational) were performed in the shear stress range of $0.1-590 \mathrm{~Pa}$ at $20^{\circ} \mathrm{C}$.

Densities were determined by helium pycnometry using a Quantachrome Multipycnometer. Morphology and compositions were determined by scanning electron microscopy (SEM) and energy dispersive X-ray spectroscopy (EDX) using a JEOL JSM-7100F system with an acceleration voltage set 
to $15 \mathrm{keV}$ and an emission current of $8 \mu \mathrm{A}$. The samples were carbon coated by vapour deposition before EDX analysis and gold coated before SEM analysis.

Raman spectroscopy was performed using a Renishaw InVia Reflex Raman Microscope fitted with a cooled charged coupled detector (CCD). A wavelength of $532 \mathrm{~nm}$ was used for all measurements.

Powder X-ray diffraction (XRD) was performed using a PANalytical X'Pert Powder diffractometer fitted with an $X^{\prime}$ Celerator $\mathrm{Cu}-\mathrm{K} \alpha_{1}$ source $(\lambda=1.5406 \AA)$ and a PIXcel ${ }^{1 \mathrm{D}}$ detector. The step size was set to $0.05^{\circ}$ and the scan speed was $0.03^{\circ} \cdot \mathrm{s}^{-1}$.

To investigate the thermal stability of the glasses, transition temperatures and weight loss upon heating were determined by simultaneous differential scanning calorimetry (DSC) and thermogravimetric analysis (TGA) using a TA Instruments SDT Q600 instrument. The analyses were carried out in air from $25-1000^{\circ} \mathrm{C}$ at a heating rate of $10^{\circ} \mathrm{C} \cdot \mathrm{min}^{-1}$ in an alumina crucible.

\subsection{Antibacterial assay}

\subsubsection{Zones of inhibition}

Stock solution for each glass composition were prepared at $1 \mathrm{mg} \cdot \mathrm{mL}^{-1}$ and $5 \mathrm{mg} \cdot \mathrm{mL}^{-1}$. Glass powders of each composition were dissolved in deionised water and incubated at $37^{\circ} \mathrm{C}$ with mixing of $200 \mathrm{rpm}$ for 24 hours. Following incubation, stock solutions were filter sterilised using $0.2 \mu \mathrm{m}$ Ministart syringe filter (Sartorius Biotech, Germany). The dissolution products of these stock solutions were loaded onto filter paper discs by adding $20 \mu \mathrm{L}$ of each stock solution in quadruplicate, and air dried. This loading procedure led to the four discs loaded with $20 \mu \mathrm{g}$ of glass dissolution products and four discs loaded with $100 \mu \mathrm{g}$. A $10^{6} \mathrm{cfu} \cdot \mathrm{mL}^{-1}$ cell suspension of S. aureus (ATCC 6538) in nutrient broth was used to create a lawn of bacteria on Oxoid Iso-Sensitestm agar plates. The discs were placed onto the plates and pressed lightly. The plates were incubated at $37^{\circ} \mathrm{C}$ overnight, after which the inhibition zones were measured $(\mathrm{mm})$.

\subsubsection{Minimum inhibitory concentration and minimum bactericidal concentration tests}

The minimum inhibitory concentration (MIC) and minimum bactericidal concentration (MBC) were determined using the microdilution method in accordance with the Clinical \& Laboratory Standards Institute (CSLI) guidelines. Stock solutions for each glass were prepared at $10 \mathrm{mg} \cdot \mathrm{mL}^{-1}$ concentration. The stock solutions were double diluted to produce ten solutions for each glass 
ranging from $5 \mathrm{mg} \cdot \mathrm{mL}^{-1}-10 \mu \mathrm{g} \cdot \mathrm{mL}^{-1}$. This double dilution was performed by setting up triplicate wells in a round bottom 96-well microtiter plate (Fisher Scientific, Leicestershire, U.K.) and $100 \mu \mathrm{L}$ nutrient broth (Oxoid Ltd, U.K.) added to each well, followed by $100 \mu \mathrm{L}$ of stock antibacterial solution to the first well, which was subsequently diluted to produce the 10 concentrations for each glass. To maintain equal volumes, $100 \mu \mathrm{L}$ was discarded from the final well after dilution. The samples were inoculated with $10^{5} \mathrm{cfu} \cdot \mathrm{mL}^{-1}$ of $\mathrm{S}$. aureus and incubated overnight at $37^{\circ} \mathrm{C}$ in a static incubator. A control containing no antibacterial stock solution was also prepared and left in the same growth conditions.

After the incubation period, the turbidity of the solutions was measured to determine the MIC, defined as the lowest concentration which showed no turbidity. The MBC was measured by taking the MIC solution along with the higher concentration solutions and controls, plating the solutions onto nutrient agar and incubating overnight at $37{ }^{\circ} \mathrm{C}$ in an aerobic environment. The $\mathrm{MBC}$ was determined as the lowest concentration in which three logarithmic reductions $(99.9 \%)$ of the $\mathrm{cfu} \cdot \mathrm{mL}^{-1}$, compared to the control was observed. All tests were performed in triplicate.

\section{Results and Discussion}

Addition of $\mathrm{Ca}^{2+}$ ions to the sodium polyphosphate solution results in phase separation with the formation of a dense, opaque lower layer (polyphosphate coacervate) and an upper aqueous layer (Figure 1A). After removal of the supernatant aqueous layer, coacervates containing different silver loadings were dried in a vacuum desiccator for 48 hours to obtain the glasses (Figure 1B). Further calcination produces self-standing glass monoliths (Figure 1C-E).

The as-made wet coacervate samples will be hereafter indicated as C (undoped) and C-AgY (doped), whereas dried glass samples are indicated as G-X (undoped) and G-AgY-X (doped) where Y $=$ mol\% $\mathrm{Ag}_{2} \mathrm{O}$ and $\mathrm{X}=\mathrm{RT}$ (vacuum dried at room temperature) or drying temperature $\left(300{ }^{\circ} \mathrm{C}\right.$ or 400 $\left.{ }^{\circ} \mathrm{C}\right)$. 


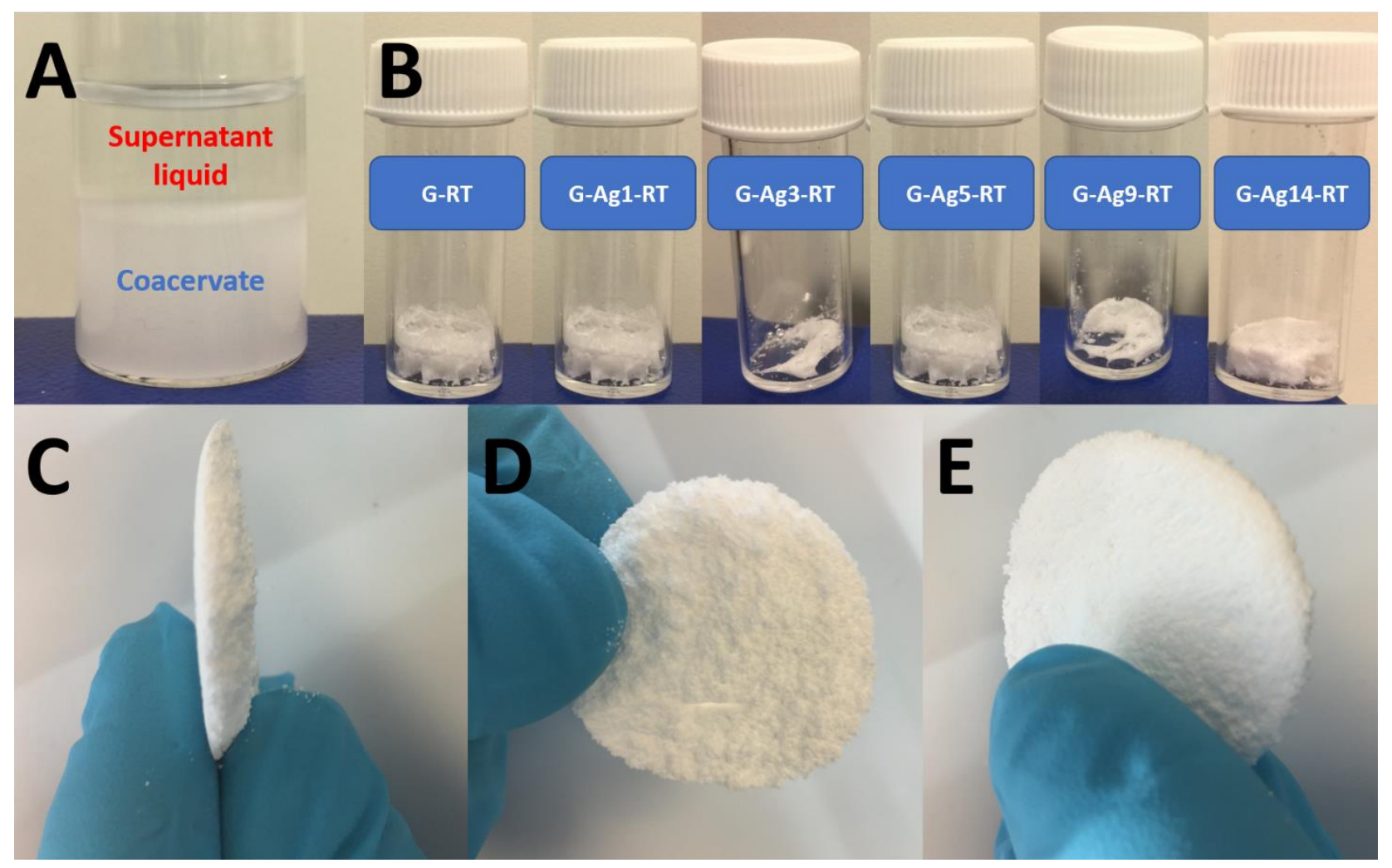

Figure 1: A: Phase separation between coacervate and aqueous supernatant liquid; B: images of coacervates after drying in vacuum desiccator at RT; C-E: images of undoped phosphate-based glass monolith after calcination at $300^{\circ} \mathrm{C}$.

\subsection{Polyphosphates coacervates}

\subsection{1 ${ }^{31} P N M R$}

Liquid state ${ }^{31} \mathrm{P}$ NMR was used to investigate the chain length of all the as-made wet coacervates and of the sodium polyphosphate precursor (NaPP) used for their synthesis. Spectra of both NaPP and of the doped and undoped coacervates are reported in Figure 2. 


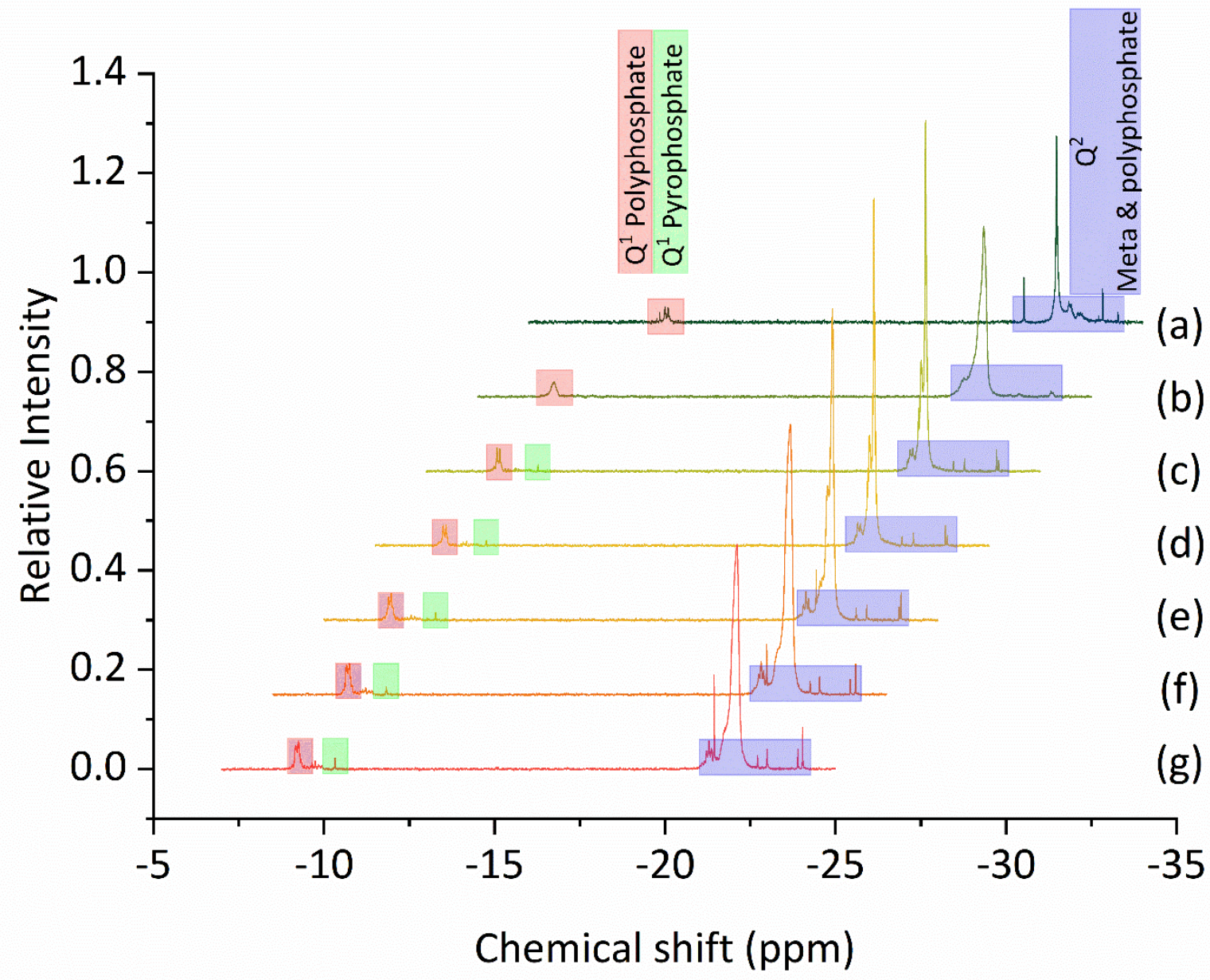

Figure 2: Liquid ${ }^{31}$ P NMR spectra of (a) NaPP (b) C; (c) C-Ag1; (d) C-Ag3; (e) C-Ag5; (f) C-Ag9 and (g) CAg14. All spectra, except for $(\mathrm{g})$ have been shifted upfield for clarity. The coloured regions represent the different phosphate environments as follows: $Q^{1}$ polyphosphate, terminal (red); $Q^{1}$ pyrophosphate (green); $\mathrm{Q}^{2}$ meta and polyphosphate, bridging (blue).

Two main groups of resonances can be observed in all samples, one in the range -8 to -11 ppm and another ranging between -21 to $-24 \mathrm{ppm}$. These groups of resonances can be described using the $Q^{n}$ terminology. This terminology explains the way the tetrahedral units are linked, where $n$ represents the number of bridging oxygens; $\mathrm{Q}^{0}$ corresponds to orthophosphate environments, $\mathrm{Q}^{1}$ units refers to terminal, end of chain, phosphorus environments of both polyphosphates and pyrophosphates $\left(\mathrm{P}_{2} \mathrm{O}_{7}\right)^{4-}$ and $\mathrm{Q}^{2}$ units represent bridging, middle of chain or ring, phosphorus environments of both meta and polyphosphates. The group of resonances observed at -8 to $-11 \mathrm{ppm}$ are indicative of $Q^{1}$ units and the group observed at -21 to $-24 p p m$ are indicative of $Q^{2}$ units. Among the $\mathrm{Q}^{1}$ units, polyphosphate and pyrophosphate groups can be distinguished as the polyphosphate units occur at more positive chemical shift values than the pyrophosphate ones. ${ }^{19}$ The two peaks observed at ca. $-9 \mathrm{ppm}$ in samples C-Ag1 to C-Ag14 can be attributed to terminal $\mathrm{Q}^{2}$ environments of both long-chain polyphosphate and tripolyphosphates. It has been reported that these environments 
present themselves as a pair of doublets, the doublet for the tripolyphosphate anion $\left(\mathrm{P}_{3} \mathrm{O}_{10}\right)^{5-}$ presenting at a slightly higher chemical shift than the terminal $Q^{2}$ environments of long-chain polyphosphates; however, this pair of doublets could not be fully resolved in these NMR experiments. ${ }^{39}$ Pyrophosphate $\left(\mathrm{P}_{2} \mathrm{O}_{7}\right)^{4-}$ peaks are observed only in the samples containing silver at ca. $-10.25 \mathrm{ppm}$. This observation suggests that chain scission is occurring in the coacervates as they are doped with silver. It has been shown that scission of polyphosphates in coacervates occurs over time in water and that the primary route for degradation is through the formation of pyrophosphate followed by breakdown into orthophosphate. ${ }^{19}$ The $Q^{1}$ and $Q^{2}$ peaks were initially shifted downfield from the (a) to (b) due to the addition of the $\mathrm{Ca}^{2+}$, however, with increasing $\mathrm{Ag}^{+}$content these peaks are shifted increasingly upfield. This phenomenon has been reported previously ${ }^{26}$ with increasing calcium concentration and has been attributed to the initial deshielding of phosphates as electron density is pulled toward the $\mathrm{Ca}^{2+}$; however, as further cations are added to the system they begin to contribute to the electron density and hence promote shielding. Unlike other ions, such as $\mathrm{Al}^{3+}$, which have been reported to preferentially bind to $Q^{1}$ phosphate environments, this upfield shift of the $Q^{2}$ peaks suggests that $\mathrm{Ag}^{+}$is able to chelate to the middle-chain phosphate species as well as the terminal $Q^{1}$ environments. ${ }^{40}$

Liquid state ${ }^{31} \mathrm{P}$ NMR data were also used to estimate the average degree of polymerisation $\left(D_{p}\right) . D_{p}$ values for all coacervates, reported in Table 1, were calculated from the relative areas under the peaks for each group observed in the liquid ${ }^{31} \mathrm{P}$ NMR using the equation: ${ }^{28}$

$$
\mathrm{D}_{p}=\frac{2 \times\left(Q^{1}+Q^{2}\right)}{Q^{1}}
$$

Table 1: Degree of polymerisation calculated from the relative areas under the peaks for each group observed in the liquid ${ }^{31} \mathrm{P}$ NMR.

\begin{tabular}{|c|c|}
\hline Sample & D $_{\mathbf{p}}$ \\
\hline NaPP & 31 \\
\hline C & 32 \\
\hline C-Ag1 & 29 \\
\hline C-Ag3 & 30 \\
\hline C-Ag5 & 29 \\
\hline C-Ag9 & 28 \\
\hline C-Ag14 & 27 \\
\hline
\end{tabular}


It has previously been reported that the coacervates often have a similar $D_{p}$ to the NaPP originally used. ${ }^{28}$ The results obtained in the present study agree with these findings, as NaPP and coacervate $C$ have a very similar value. The $D_{p}$ of the phosphate coacervates decreases slightly in the high silver content products which again suggests that silver ions play a role in the scission of the phosphate chains in solution. It is well established that polyphosphate chains degrade in aqueous solution due to the hydrolysable nature of the P-O-P linkage allowing for nucleophilic attack by a water molecule or hydroxide ion. This process has been shown to be highly dependent on metal cations in solution and it is therefore assumed that the silver acts as a catalyst for this process. ${ }^{19}$

\subsubsection{Rheology of polyphosphates coacervates}

The viscoelastic properties of undoped and silver-doped coacervates were investigated using rheological measurements taken 24 hours after formation. This settling period was instigated as it was noted that the viscosity of the coacervates was unsteady within the first 24 hours after preparation. This is consistent with the observation that the as-made coacervates are opaque, becoming transparent after 24 hours. The turbidity has been ascribed to the presence of micrometresized water droplets that cause light scattering. ${ }^{28,41}$ The coacervates become transparent over time, the timescale for this process being dependent on the viscosity of the coacervates. ${ }^{28}$ Upon application of a shear stress in the first 24 hours after formation, the coacervates released water which in turn lubricated the measuring system and caused wall-slip. Rheological measurements after 24 hours of coacervate formation are therefore considered more reliable, as it has been shown that degradation of the polyphosphate chains within the first 48 hours is negligible. ${ }^{19}$ Steady shear viscosity measurements at $20^{\circ} \mathrm{C}$ for all coacervates are shown in Figure 3.

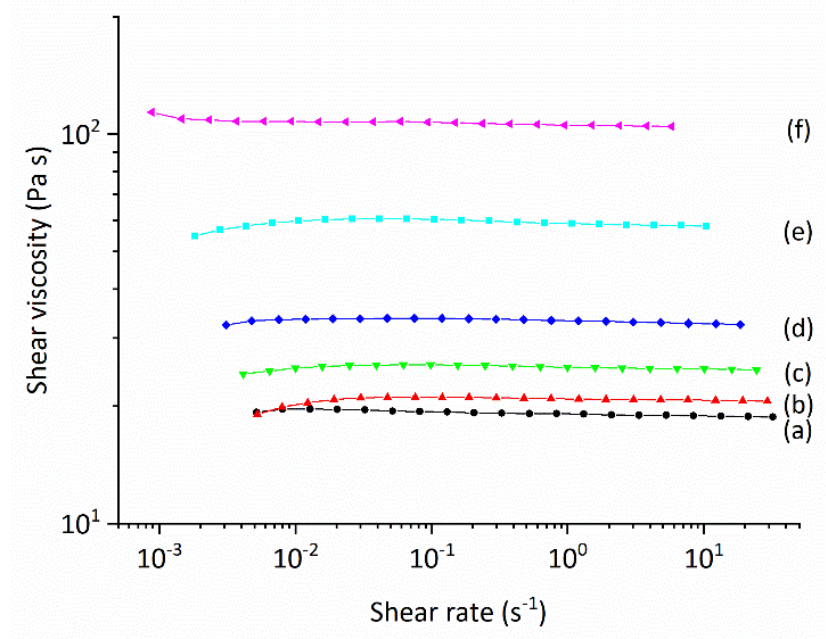


Figure 3: Shear viscosity versus shear rate for: (a) C; (b) C-Ag1; (c) C-Ag3; (d) C-Ag5; (e) C-Ag9 and (f) C-Ag14.

It is evident that the shear viscosity is largely independent of shear rate for all samples over ca. 4 orders of magnitude, indicating that the coacervates behave as Newtonian fluids. This is consistent with previous studies on $\mathrm{Ca}^{2+}$ and $\mathrm{Mg}^{2+}$ polyphosphate coacervates. ${ }^{28}$ Newtonian flow has also been observed in other types of complex polymer-based coacervates. ${ }^{42}$ The effects of divalent cation type and concentration on the viscosity of polyphosphate coacervates have also been previously reported. ${ }^{28}$ However, no reports on the effects of an additional dopant ion such as $\mathrm{Ag}^{+}$on the rheology of calcium-based polyphosphate coacervates have been published, to the authors' knowledge. Results shown in Figure 3 clearly show that an increase in viscosity correlates strongly with an increase in $\mathrm{Ag}^{+}$content. This is also evident from Figure 4, the viscosity of the undoped coacervate (19 Pa.s) is seen to increase to ca. $100 \mathrm{~Pa} \cdot \mathrm{s}$ for the $14 \mathrm{~mol} \% \mathrm{Ag}_{2} \mathrm{O}$ doped sample.

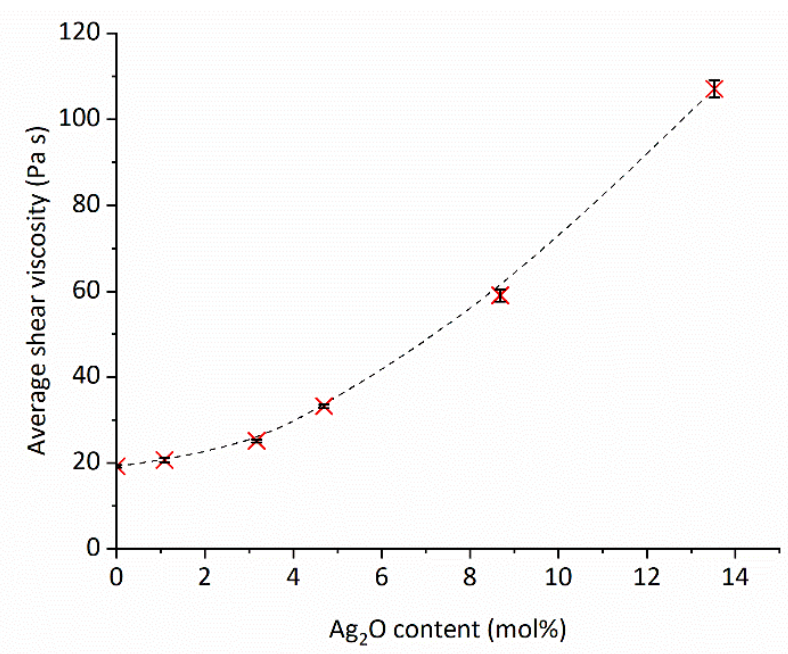

Figure 4: Average shear viscosity versus silver oxide content. The dashed line has been drawn to guide the eye.

Viscosity has been shown to be highly dependent on chain length, with longer chains producing more viscous coacervates. ${ }^{28}$ However, as shown by the ${ }^{31} P$ NMR, the $D_{p}$ of the coacervates presented here are only slightly dependant on silver concentration, with any minor changes unable to account for the marked increase in viscosity. For this reason, it can be assumed that the composition of ions and their electrostatic interactions with the polyphosphate chains are the origin for the increase in viscosity.

It has been previously reported that polyphosphate chains will coil around themselves when chelated to divalent ions such as $\mathrm{Ca}^{2+}$ and in turn the viscosity decreases markedly. ${ }^{26} \mathrm{~A}$ possible explanation for the increase in viscosity seen in the silver doped coacervates is therefore the 
disruption of this coiling and subsequent straightening of the chains, which allows for better packing and electrostatic interactions, leading to higher viscosities. The polyphosphate chains exert electrostatic repulsion to each other which the $\mathrm{Ag}^{+}$helps to screen and leads to subsequent chain association or to cross-linking effects. ${ }^{28}$

\subsection{Characterisation of dried phosphate-based glasses}

\subsubsection{Assessment of composition}

After the settling time of 24 hours, undoped and silver-doped coacervates were dried in a vacuum desiccator at room temperature for 48 hours. Determination of the compositions of vacuum dried glasses was carried out using SEM equipped with EDX detection. Compositions expressed in terms of oxide mol\% calculated assuming that the excess oxygen is charge balanced by the protons of the water are reported in Table $2 .^{23}$

Table 2: Compositions of the glasses expressed in terms of oxides mol\% based on EDX results.

\begin{tabular}{|c|c|c|c|c|c|}
\hline \multirow[t]{2}{*}{ Sample } & \multicolumn{5}{|c|}{ Oxide composition (mol\%) } \\
\hline & $\mathrm{P}_{2} \mathrm{O}_{5}$ & $\mathrm{CaO}$ & $\mathrm{Na}_{2} \mathrm{O}$ & $\mathrm{Ag}_{2} \mathrm{O}$ & $\mathrm{H}_{2} \mathrm{O}$ \\
\hline G-RT & 48 & 40 & 12 & - & 0.58 \\
\hline G-Ag1-RT & 46 & 41 & 12 & 1 & 1.29 \\
\hline G-Ag3-RT & 46 & 40 & 11 & 3 & 0.78 \\
\hline G-Ag5-RT & 46 & 41 & 9 & 5 & 0.98 \\
\hline G-Ag9-RT & 44 & 40 & 8 & 9 & 1.42 \\
\hline G-Ag14-RT & 46 & 35 & 6 & 14 & 0.45 \\
\hline
\end{tabular}

Elemental compositions and oxide compositions expressed in terms of $w t \%$ are reported in Table S1 and S2, respectively. A representative EDX spectrum used to calculate the composition of the glasses is also presented in Figure S1 (Supplementary Information). Elemental compositions were calculated using the peak areas for the elemental spectral lines. A representative EDX chemical map used to evaluate distribution of all elements is presented in Figure 5. The EDX map shows that all elements, including the silver dopant, are homogenously distributed on the surface of the glass particles. 


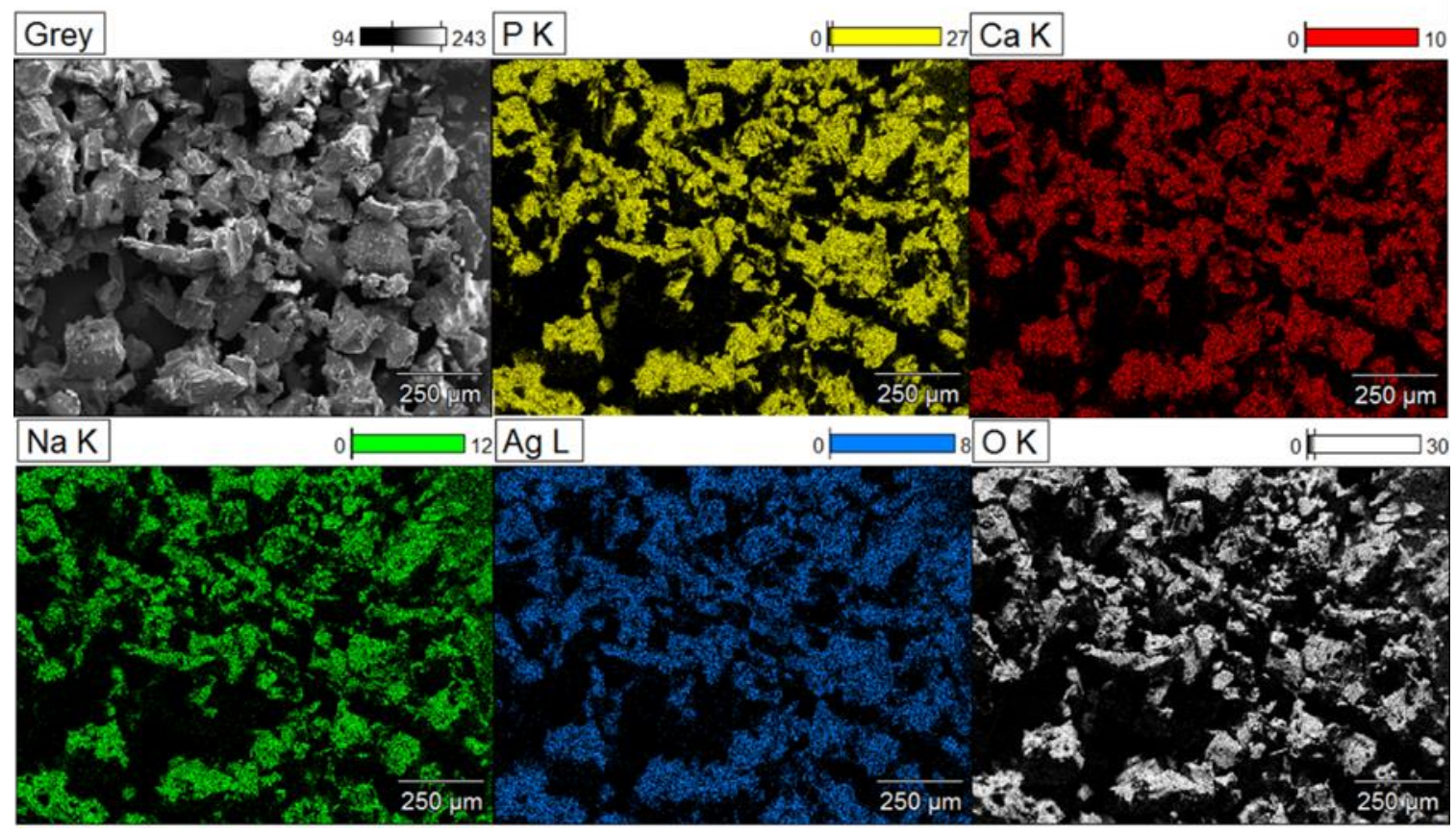

Figure 5: EDX mapping of a representative sample of G-Ag14-RT.

\subsubsection{Thermal analysis}

To assess the weight loss of all vacuum dried samples and identify thermal events upon heating, simultaneous TGA and DSC were performed (Figure 6). Main weight losses (reported as wt\%) and key thermal events are shown in Table 3. 

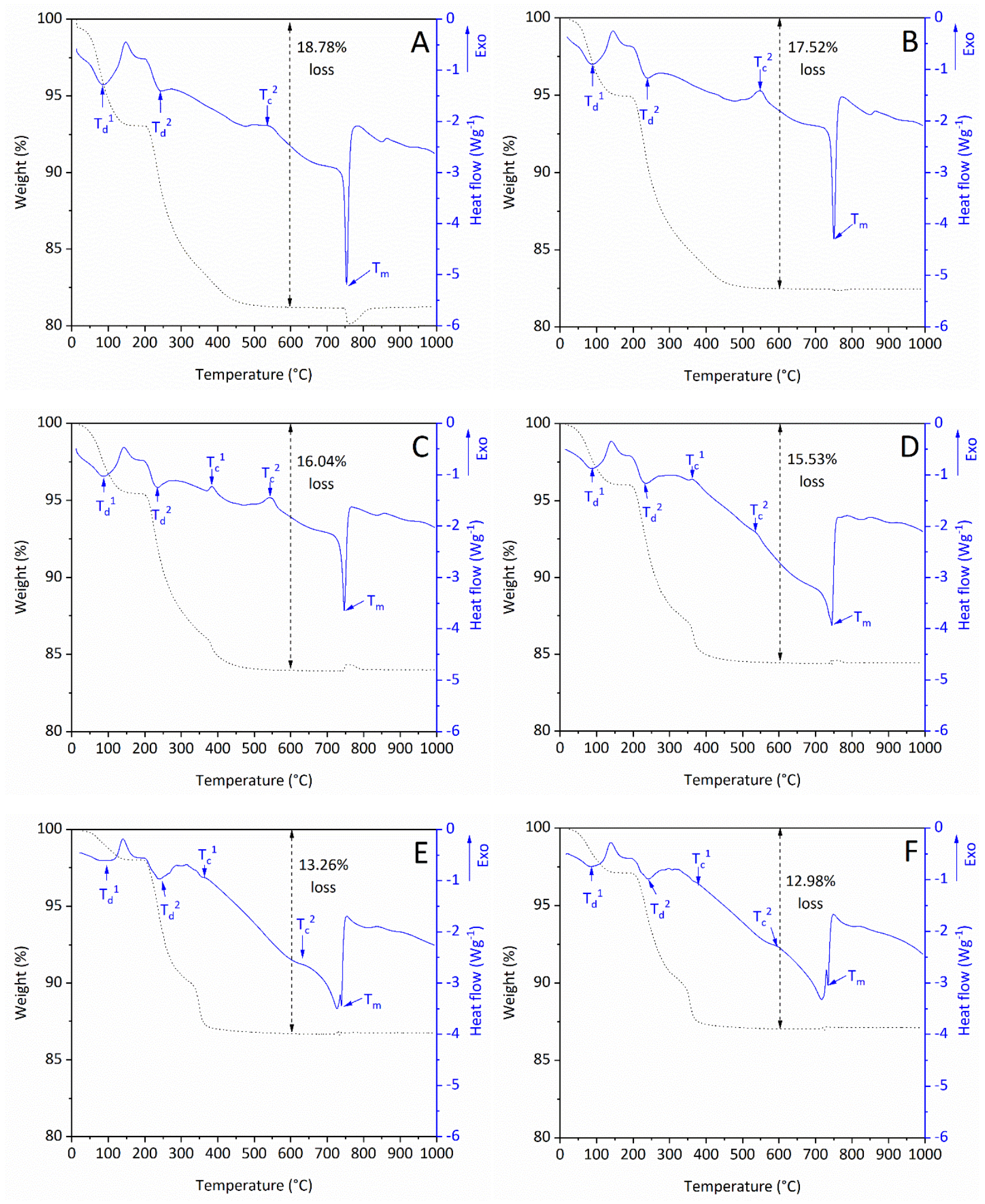

Figure 6: TGA (dotted line) and DSC (solid line) of A: G-RT; B: G-Ag1-RT; C: G-Ag3-RT; D: G-Ag5-RT; E: G-Ag9-RT and F: G-Ag14-RT.

The first weight loss (ca. $3-7$ wt\%) occurs in all glasses up to $175^{\circ} \mathrm{C}$ and it is associated with a large endothermic peak between $82-89^{\circ} \mathrm{C}$ attributed to loss of loosely bound water. The second weight loss (ca. $7.5-10$ wt\%), observed between 175 and $350{ }^{\circ} \mathrm{C}$ and associated with a large 
endothermic peak in the DSC between $200-275{ }^{\circ} \mathrm{C}$ is attributed to dehydration caused by the loss of structural water. ${ }^{23}$ Dehydration peaks are labelled $T_{d}$ on the DSC curve in Figure 6 . The third weight loss (ca. $2-4 \mathrm{wt} \%$ ) observed in the range $350-1000^{\circ} \mathrm{C}$ can be attributed to the loss of nitrates.

The broad exothermic peak observed in G-RT and G-Ag1-RT at $543^{\circ} \mathrm{C}$ and $550{ }^{\circ} \mathrm{C}$, respectively, can be ascribed to the crystallisation of the glasses. In G-Ag3-RT two broad exothermic peaks are observed at $385^{\circ} \mathrm{C}$ and $548{ }^{\circ} \mathrm{C}$ suggesting that crystallisation of two phases occurs in these systems. In G-Ag5-RT, G-Ag9-RT and G-Ag14-RT the two endothermic peaks are less evident. The endothermic peak observed at around $750{ }^{\circ} \mathrm{C}$ in all samples can be ascribed to a melting phase transition ( $T_{\mathrm{m}}$ ). It must be noted that the melting peak is sharp in G-RT, G-Ag1-RT and G-Ag3-RT. However, a broad shoulder on the left of the peak becomes prominent in G-Ag5-RT, G-Ag9-RT and G-Ag14-RT. This can explain why the two endothermic peaks due to the crystallisation are less evident in these samples.

Table 3: Weight loss \%, dehydration temperatures $\left(T_{d}{ }^{1} / T_{d}{ }^{2}\right)$, crystallisation temperatures $\left(T_{c}{ }^{1} / T_{c}{ }^{2}\right)$ and melting temperatures $\left(T_{m}\right)$ from TGA and DSC plots of all glasses.

\begin{tabular}{|c|c|c|c|c|c|c|c|c|c|}
\hline \multirow[t]{3}{*}{ Sample } & \multicolumn{4}{|c|}{ Weight loss (\%) } & \multicolumn{5}{|c|}{ Thermal events } \\
\hline & \multicolumn{3}{|c|}{ Temperature range $\left({ }^{\circ} \mathrm{C}\right)$} & \multirow[t]{2}{*}{ Total } & \multirow[t]{2}{*}{$T_{d}{ }^{1}$} & \multirow[t]{2}{*}{$T_{d^{2}}{ }^{2}$} & \multirow[t]{2}{*}{$T_{c}{ }^{1}$} & \multirow[t]{2}{*}{$\mathrm{T}_{\mathrm{c}}{ }^{2}$} & \multirow[t]{2}{*}{$T_{m}$} \\
\hline & $25-175$ & $175-350$ & $350-1000$ & & & & & & \\
\hline G-RT & 6.9 & 9.3 & 2.6 & 18.8 & 85 & 221 & - & 543 & 754 \\
\hline G-Ag1-RT & 5.0 & 9.9 & 2.6 & 17.5 & 89 & 219 & - & 550 & 750 \\
\hline G-Ag3-RT & 4.5 & 9.0 & 2.5 & 16.0 & 89 & 214 & 385 & 548 & 747 \\
\hline G-Ag5-RT & 4.0 & 8.9 & 2.7 & 15.6 & 88 & 212 & 364 & 539 & 745 \\
\hline G-Ag9-RT & 1.9 & 7.5 & 3.7 & 13.2 & 83 & 238 & 368 & 644 & 739 \\
\hline G-Ag14-RT & 2.9 & 7.8 & 2.3 & 13.0 & 83 & 218 & 375 & 599 & 735 \\
\hline
\end{tabular}

\subsubsection{X-ray diffraction}

X-ray diffraction patterns of all vacuum dried glasses are reported in Figure 7A. No Bragg peaks are observed indicating that all samples are amorphous. The only feature observed is the broad halo around $25^{\circ}$ which is due to the amorphous phosphate network.

The X-ray diffraction patterns of glasses after calcination at $300{ }^{\circ} \mathrm{C}$ and $400{ }^{\circ} \mathrm{C}$ are reported in Figure $7 \mathrm{~B}$ and $7 \mathrm{C}$, respectively. The broad halo around $25^{\circ}$ is still present in all samples confirming the presence of the phosphate network. 

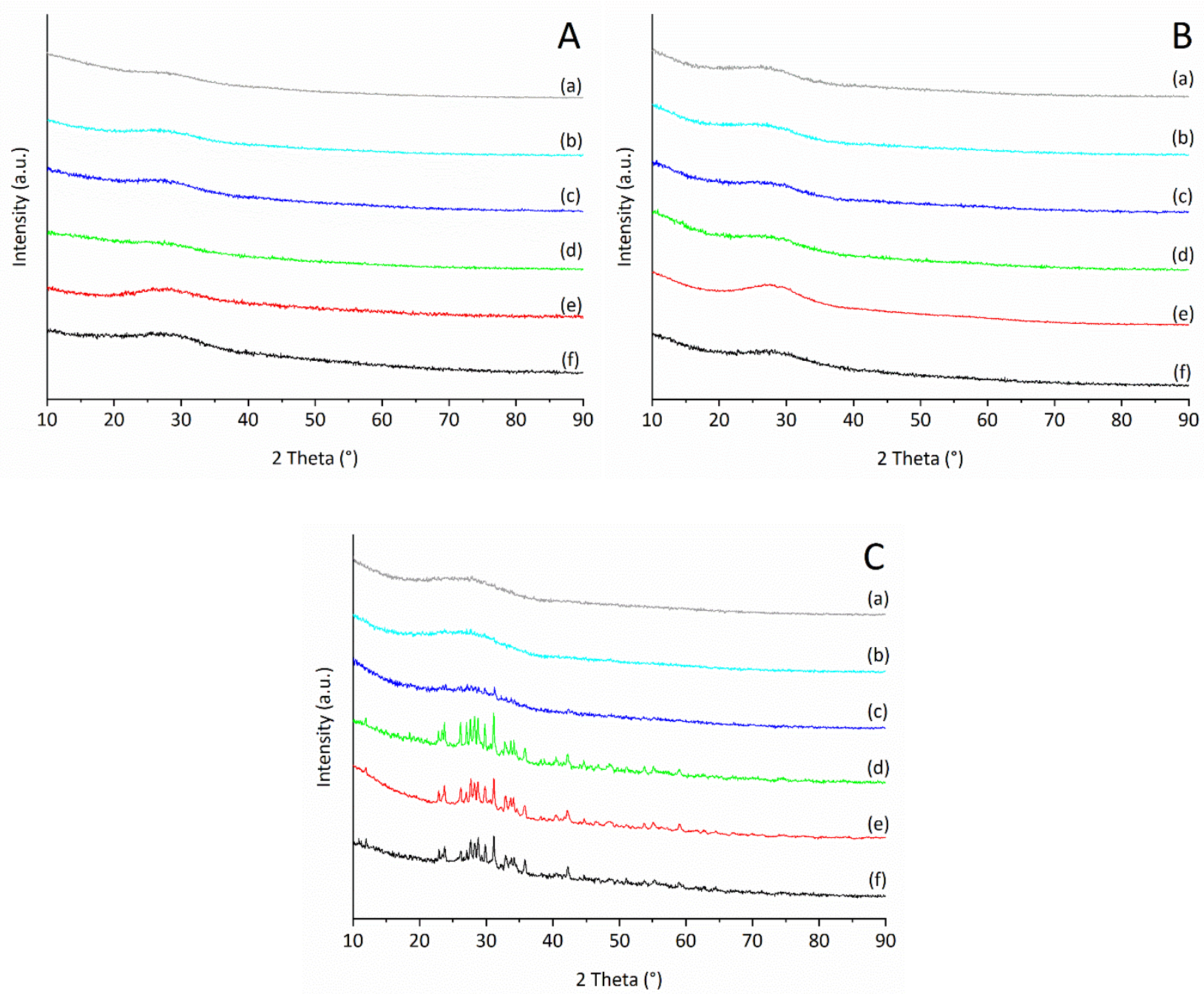

Figure 7: XRD patterns of A: (a) G-RT; (b) G-Ag1-RT; (c) G-Ag3-RT; (d) G-Ag5-RT; (e) G-Ag9-RT and (f) G-Ag14-RT. B: (a) G-300; (b) G-Ag1-300; (c) G-Ag3-300; (d) G-Ag5-300; (e) G-Ag9-300 and (f) G-Ag14300. C: (a) G-400; (b) G-Ag1-400; (c) G-Ag3-400; (d) G-Ag5-400; (e) G-Ag9-400 and (f) G-Ag14-400.

XRD patterns of all samples after calcination at $300{ }^{\circ} \mathrm{C}$ do not show Bragg peaks indicating that they have remained amorphous. The amorphous structure is also preserved after calcination at $400{ }^{\circ} \mathrm{C}$ in the samples G-400, G-Ag1-400 and G-Ag3-400, whereas precipitation of a mixture of crystalline phases that could be ascribed to calcium silver phosphate, $\mathrm{CaAg}\left(\mathrm{PO}_{3}\right)_{3}$ (PDF card number 00-023-0126), and calcium pyrophosphate, $\beta-\mathrm{Ca}_{2} \mathrm{P}_{2} \mathrm{O}_{7}$ (PDF card number 01-071-2123) is observed in G-Ag5-400, G-Ag9-400 and G-Ag14-400. These results agree with the thermal analysis, which show that the crystallisation of G-RT and G-Ag1-RT occurs at temperatures higher than $400{ }^{\circ} \mathrm{C}$, whereas the crystallisation of all other glasses occurs below $400{ }^{\circ} \mathrm{C}$. 


\subsubsection{Raman spectroscopy}

Raman spectra of the vacuum dried glasses, glasses after calcination at $300^{\circ} \mathrm{C}$ and $400{ }^{\circ} \mathrm{C}$ are shown in Figure 8. A detailed assignment of the Raman bands for all systems are reported in Table S3 (Supplementary Information). All spectra of vacuum dried glasses and glasses after calcination at $300{ }^{\circ} \mathrm{C}$ are typical of amorphous phosphate systems. In both cases, no significant differences are observed between glasses with different silver loadings indicating that the bonding in the phosphate network is not strongly affected by the addition of silver.
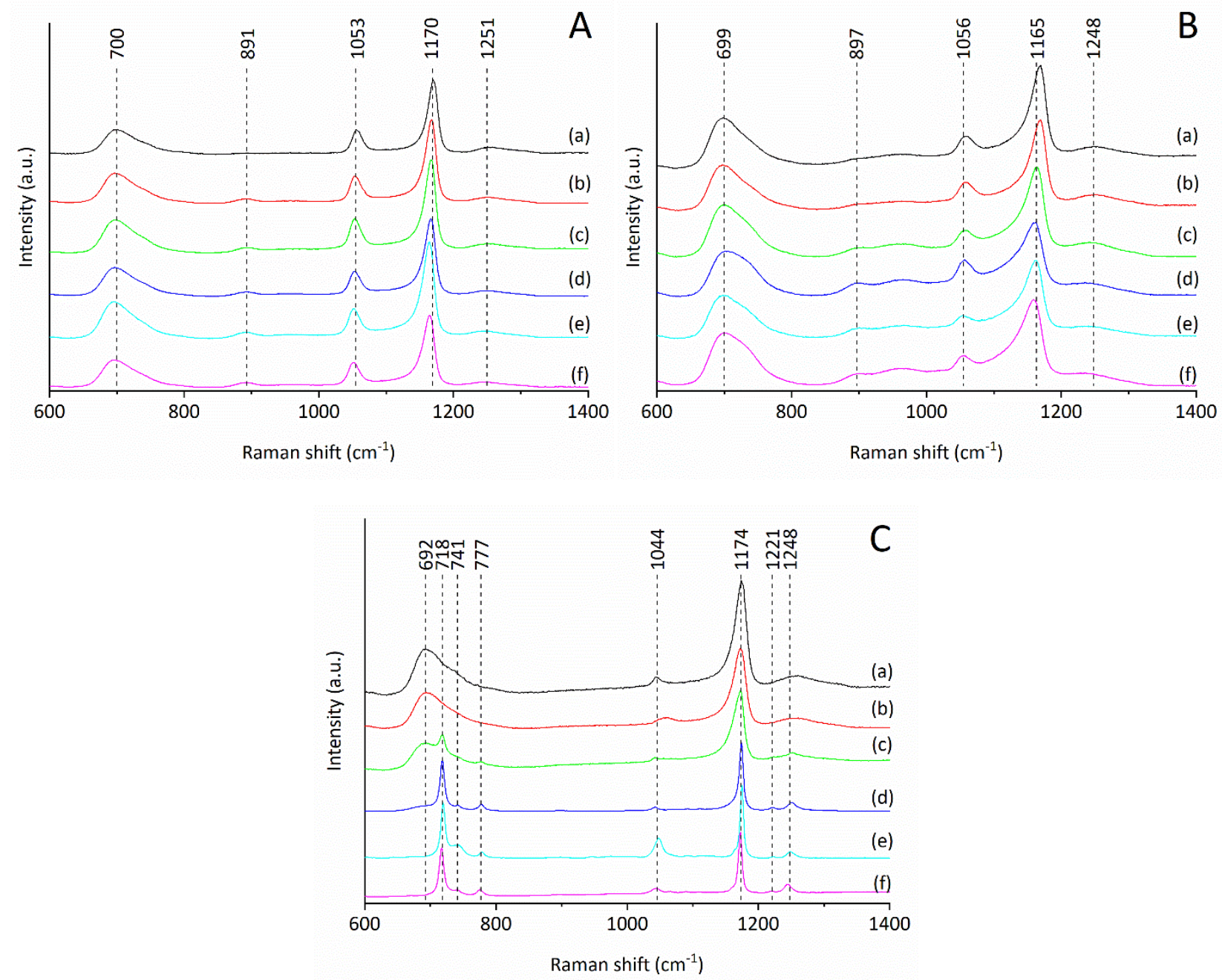

Figure 8: Raman spectra of A: (a) G-RT; (b) G-Ag1-RT; (c) G-Ag3-RT; (d) G-Ag5-RT; (e) G-Ag9-RT and (f) G-Ag14-RT. B: (a) G-300; (b) G-Ag1-300; (c) G-Ag3-300; (d) G-Ag5-300; (e) G-Ag9-300 and (f) G-Ag14300. C: (a) G-400; (b) G-Ag1-400; (c) G-Ag3-400; (d) G-Ag5-400; (e) G-Ag9-400and (f) G-Ag14-400.

In Figures $8 \mathrm{~A}$ and $\mathrm{B}$, five main stretching frequencies are observed at approximately 700,900 , 1050, 1170 and $1250 \mathrm{~cm}^{-1}$. The absorption bands at around 700 and $900 \mathrm{~cm}^{-1}$ are attributed to the symmetrical and asymmetrical stretching modes of the in-chain P-O-P bridging oxygen (P-O $\mathrm{b}$ ), respectively. ${ }^{30,43,44}$ The bands at around 1170 and $1250 \mathrm{~cm}^{-1}$ are attributed to the symmetric and 
asymmetric stretching modes of the out of chain $\left(\mathrm{P}-\mathrm{O}_{\mathrm{t}}\right)$, respectively. ${ }^{45}$ The band at around $1050 \mathrm{~cm}^{-}$

1 is assigned to the symmetrical stretching of the $\left(\mathrm{PO}_{3}\right)^{2-}{ }_{t}$ species. ${ }^{21,30,46}$ The lack of a strong peak in the $950-1000 \mathrm{~cm}^{-1}$ range suggests that the glasses do not contain orthophosphate species as these usually show a sharp, strong band within this region. ${ }^{46,47}$

On heat treatment of samples at $300{ }^{\circ} \mathrm{C}$ (Figure 8B), the Raman spectra look very similar to the vacuum dried ones indicating that calcination does not greatly affect the structure; however, a broadening of the peaks is observed.

More significant changes are observed after calcination of the samples at $400^{\circ} \mathrm{C}$ (Figure $8 \mathrm{C}$ ). Spectra of G-400 and G-Ag1-400 are very similar to the corresponding glasses calcined at $300{ }^{\circ} \mathrm{C}$, showing mainly wide bands typical of amorphous phases. In G-Ag3-400, however, a small sharp peak appears at around $718 \mathrm{~cm}^{-1}$, indicative of P-O-P stretching in pyrophosphate or short-chain metaphosphate species suggesting that upon calcination at $400{ }^{\circ} \mathrm{C}$ scission of the phosphate chain is occurring. ${ }^{48}$ This observation is further backed up by the diminishment of both the symmetric stretching mode of the in-chain polyphosphate P-O-P bridging oxygen at around $700 \mathrm{~cm}^{-1}$ and the asymmetrical stretching mode at $900 \mathrm{~cm}^{-1}$. New small bands appear at around 740, 780 and $1220 \mathrm{~cm}^{-}$

${ }^{1}$ which can be assigned to the symmetric stretching of P-O-P modes and asymmetric stretching of $\left(\mathrm{PO}_{3}\right)^{2-}{ }_{t}$ in crystalline calcium pyrophosphate. ${ }^{44}$

Raman spectra of G-Ag5-400, G-Ag9-400 and G-Ag14-400 show much sharper peaks than the glasses with lower silver content; this has been attributed to crystallisation of the glasses and a diminished amorphous phase. This is in agreement with the DSC and XRD data, which show that the silver content has a significant role to play in crystallisation due to its involvement in the scission of long-chain phosphate species at high temperatures.

\subsubsection{Scanning Electron Microscopy and density}

The morphology of the undoped glasses before and after calcination was investigated using SEM (Error! Reference source not found.). Error! Reference source not found.A shows that G-RT, dried in the vacuum desiccator is composed of angular shape, smooth surface particles. After calcination at $300{ }^{\circ} \mathrm{C}$ and $400{ }^{\circ} \mathrm{C}$, glasses show increased porosity/fragmentation (Figure 9B and 9C). This is likely caused by water release during heating. ${ }^{49}$ 


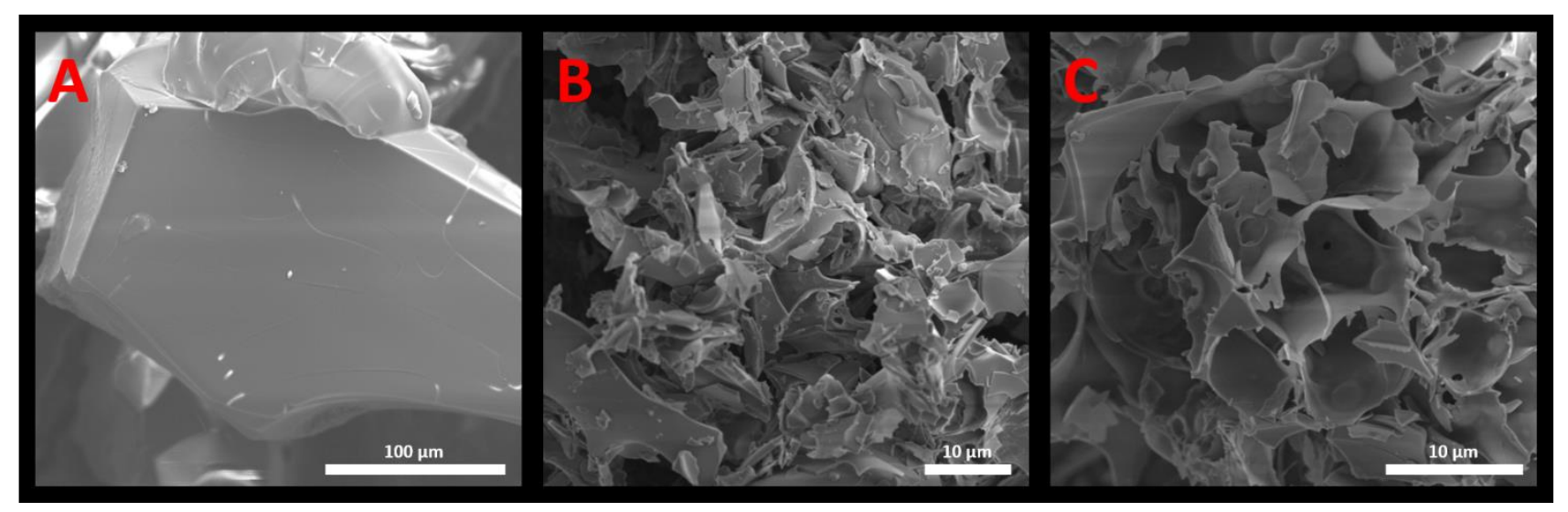

Figure 9: SEM images of A: G-RT, B: G-300 and C: G-400.

SEM observations are supported by density measurements. The density of G-RT was determined to be $2.13 \mathrm{~g} \cdot \mathrm{cm}^{-3}$ which is similar to the density of phosphate-based glasses prepared by $\mathrm{MQ}\left(\mathrm{ca} .2 .60 \mathrm{~g} \cdot \mathrm{cm}^{-3}\right) .{ }^{50,51}$ The density of G-RT decreases considerably after calcination at $300^{\circ} \mathrm{C}(1.40$ $\left.\mathrm{g} \cdot \mathrm{cm}^{-3}\right)$ and $400{ }^{\circ} \mathrm{C}\left(1.14 \mathrm{~g} \cdot \mathrm{cm}^{-3}\right)$ probably due to the porous structure formed by dehydration of the samples during heating.

\subsection{Antibacterial properties}

In vitro testing of the vacuum dried glasses for antimicrobial activity against $S$. aureus was performed using the disc agar diffusion method. Discs were loaded with $20 \mu \mathrm{g}$ (Figure 10A) and 100 $\mu \mathrm{g}$ (Figure 10B) of glass dissolution products for each composition. The clear zones around the white discs show regions of bacterial inhibition. Zones of inhibition clearly increase as silver content increases. Average zones of inhibition for all glasses are summarised in Table 4. 


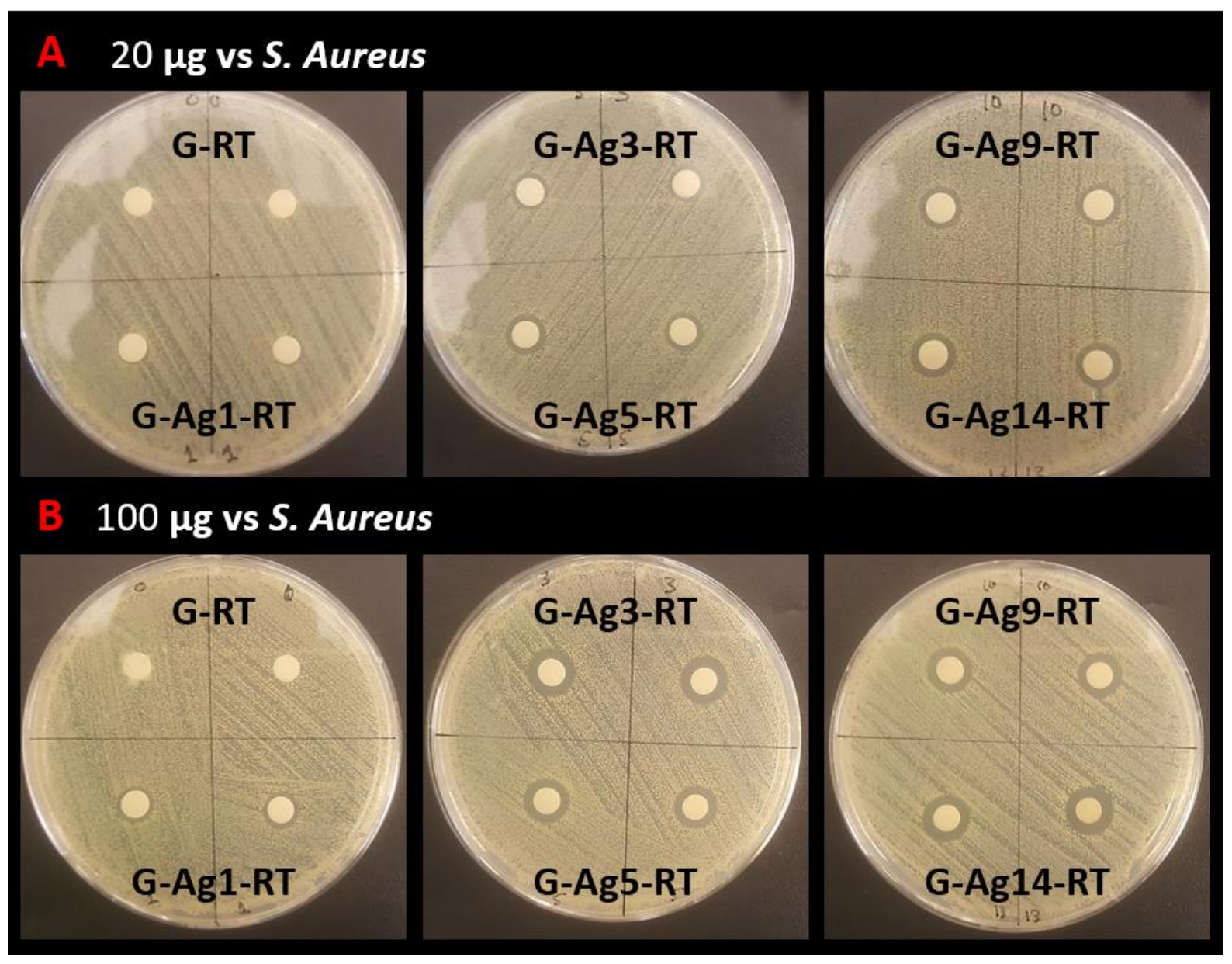

Figure 10: Zones of inhibition generated by $A: 20 \mu \mathrm{g}$ of dissolution products and $\mathrm{B}: 100 \mu \mathrm{g}$ dissolution products of the glasses G-RT, G-Ag1-RT, G-Ag3-RT, G-Ag5-RT, G-Ag9-RT and G-Ag14-RT in contact with S. aureus.

Table 4: Zones of inhibition (average of 4 repeats) for discs loaded with 20 and $100 \mu \mathrm{g}$ of dissolution products, MIC and MBC data for all glasses.

\begin{tabular}{|c|c|c|c|c|}
\hline Sample & $\begin{array}{c}\text { Average zone of } \\
\text { inhibition for } 20 \mu \mathrm{g} \\
\operatorname{discs}(\mathrm{mm})\end{array}$ & $\begin{array}{c}\text { Average zone of } \\
\text { inhibition for } 100 \mu \mathrm{g} \\
\operatorname{discs}(\mathrm{mm})\end{array}$ & $\mathrm{MIC}\left(\mu \mathrm{g} \cdot \mathrm{mL}^{-1}\right)$ & $\mathrm{MBC}\left(\mu \mathrm{g} \cdot \mathrm{mL}^{-1}\right)$ \\
\hline G-RT & 0.00 & 0.00 & $>5000$ & $>5000$ \\
\hline G-Ag1-RT & 0.00 & 8.50 & 625 & 1250 \\
\hline G-Ag3-RT & 8.75 & 10.75 & 39.1 & 78.1 \\
\hline G-Ag5-RT & 10.00 & 11.00 & 19.5 & 39.1 \\
\hline G-Ag9-RT & 10.25 & 12.00 & 19.5 & 39.1 \\
\hline G-Ag14-RT & 11.00 & 12.25 & 9.7 & 39.1 \\
\hline
\end{tabular}

MICs and MBCs presented in Figure 11 show a dose dependant antimicrobial effect. An increase in antimicrobial activity was observed with an increasing concentration of silver. Glass 
sample containing highest concentration of silver (G-Ag14-RT) demonstrated greatest antimicrobial effect with MIC and MBC values being 65 and 32 times less than that of the 1 mol\% doped glass (GAg1-RT). However, the $\mathrm{MBC}$ shows a plateau forming at ca. $7.5 \mathrm{~mol} \% \mathrm{Ag}_{2} \mathrm{O}$, suggesting that this may be the optimum silver content of the glass which allows for the greatest bactericidal properties to silver content ratio. Due to the cytotoxicity which may arise from excess silver and the expense of silver nitrate makes this composition optimal. Further tests needs to be done on the cytotoxicity of these concentrations of silver. ${ }^{52}$

The MIC results also shows a similar trend to that of the $M B C$ however the glass doped with $14 \mathrm{~mol} \% \mathrm{Ag}_{2} \mathrm{O}$ requires a lower concentration to inhibit of the growth of bacteria.

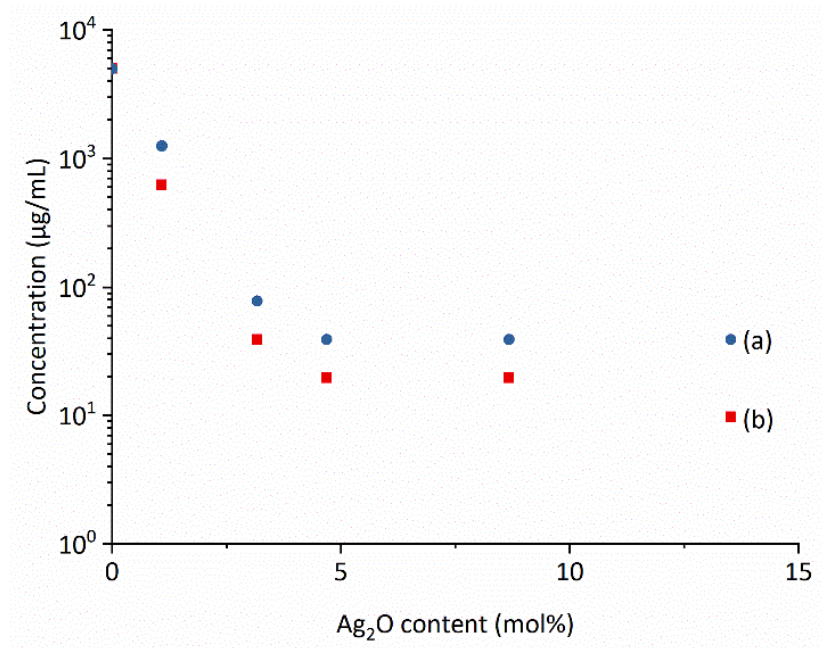

Figure 11 : Graphical representation of the (a) MBC and (b) MIC data shown in Table 4.

\section{Conclusions}

Glasses in the $\mathrm{P}_{2} \mathrm{O}_{5}-\mathrm{CaO}-\mathrm{Na}_{2} \mathrm{O}$ system doped with various amounts of $\mathrm{Ag}_{2} \mathrm{O}(0,1,3,5,9$ and 14 mol\%) have been successfully synthesised via the facile, water-based coacervate method. The asprepared coacervates have been analysed using rheology and liquid state ${ }^{31} \mathrm{P}$ NMR.

The viscosity of the coacervate has been found to be highly dependent on the silver content which is attributed to disruption of the coiling phenomenon which occurs in polyphosphate solutions in the presence of divalent ions, the disruption of which allows for stronger interactions between polyphosphate chains. ${ }^{31}$ P NMR experiments suggest that degradation of the polyphosphate chains within the timeframe of glass production is not significant and that the silver ions bind to both $Q^{1}$ and $\mathrm{Q}^{2}$ environments. ${ }^{31} \mathrm{P}$ NMR has also shown that the degree of polymerisation of the polyphosphate coacervates is similar to the sodium polyphosphate originally used and decreases slightly with increasing silver content. 
After drying at room temperature followed by calcination at $300{ }^{\circ} \mathrm{C}$ and $400{ }^{\circ} \mathrm{C}$, the coacervates became solid, self-standing materials. XRD, Raman spectroscopy and thermal analysis have shown that samples are all amorphous up to $300^{\circ} \mathrm{C}$ regardless of their composition. However, after calcination at $400{ }^{\circ} \mathrm{C}$, crystallisation occurs in samples with $\mathrm{Ag}_{2} \mathrm{O}$ content higher than 3 mol\%.

The melting point of all glasses was found to be between $735-754{ }^{\circ} \mathrm{C}$ with the $T_{m}$ of the samples decreasing with higher silver content glasses. Structural characterisation has shown that silver content has a significant role in the scission of the phosphate chains with increasing calcination temperature.

The growth of $S$. aureus was significantly inhibited by glass dissolution products, showing that higher silver concentration glasses provide greater antibacterial properties, bactericidal and inhibitory. A theoretical glass composition containing 7.5 mol\% $\mathrm{Ag}_{2} \mathrm{O}$ is predicted to be the most efficient in terms of greatest antibacterial activity; it is observed that glasses with $\mathrm{Ag}_{2} \mathrm{O}$ content higher than 7.5 mol\% show only small improvement in the antibacterial properties.

Silver-doped phosphate-based glasses prepared by the coacervation method offer an excellent alternative to the traditional melt-quenched glasses and have a considerable potential as bioresorbable antimicrobial materials.

\section{Acknowledgments}

The authors would like to acknowledge the EPSRC (grant EP/P033636/1) and Royal Society (grant RSG $\backslash R 1 \backslash 180191$ ) for providing the funding to conduct this study. The authors are also grateful to Dr M. Ramaioli, Mr S. Melides and Mr P. Rando, Department of Chemical and Process Engineering, University of Surrey, for their help with the rheology measurements and Dr D. Jones and Miss A. M. Nelson for their help with the SEM/EDX.

\section{$\underline{\text { References }}$}

1 G. Kaur, G. Pickrell, N. Sriranganathan, V. Kumar and D. Homa, J. Biomed. Mater. Res. Part BApplied Biomater., 2016, 104, 1248-1275.

I. D. Xynos, M. V. J. Hukkanen, J. J. Batten, L. D. Buttery, L. L. Hench and J. M. Polak, Calcif. Tissue Int., 2000, 67, 321-329.

J. A. Roether, A. R. Boccaccini, L. L. Hench, V. Maquet, S. Gautier and R. Jérôme, Biomaterials, 
$2002,23,3871-3878$.

M. N. Rahaman, X. Liu, B. S. Bal, D. E. Day, L. Bi and L. F. Bonewald, Ceram. Trans., 2012, 237, 73-82.

M. T. Souza, S. Tansaz, E. D. Zanotto and A. R. Boccaccini, Materials (Basel)., 2017, 10, 1-14.

L. L. Hench and J. R. Jones, Front. Bioeng. Biotechnol., 2015, 3, 1-12.

7

A. Tilocca, A. N. Cormack and N. H. De Leeuw, Chem. Mater., 2007, 19, 95-103.

8

R. P. Brannigan and A. P. Dove, Biomater. Sci., 2017, 5, 9.

9

J. C. Knowles, J. Mater. Chem., 2003, 13, 2395-2401.

10

D. M. Pickup, R. J. Newport and J. C. Knowles, J. Biomater. Appl., 2012, 26, 613-622.

11

A. M. Mulligan, M. Wilson and J. C. Knowles, Biomaterials, 2003, 24, 1797-1807.

12

A. M. Mulligan, M. Wilson and J. C. Knowles, J. Biomed. Mater. Res. - Part A, 2003, 67, 401412.

M. K. Narayanan and H. D. Shashikala, Procedia Mater. Sci., 2014, 5, 303-310.

14

G. J. Owens, R. K. Singh, F. Foroutan, M. Alqaysi, C.-M. Han, C. Mahapatra, H.-W. Kim and J. C. Knowles, Prog. Mater. Sci., 2016, 77, 1-79.

15

D. M. Pickup, P. Guerry, R. M. Moss, J. C. Knowles, M. E. Smith and R. J. Newport, J. Mater. Chem., 2007, 17, 4777.

16

D. Carta, D. M. Pickup, J. C. Knowles, M. E. Smith and R. J. Newport, J. Mater. Chem., 2005, 15, 2134-2140.

17 D. Carta, D. M. Pickup, J. C. Knowles, I. Ahmed, M. E. Smith and R. J. Newport, J. Non. Cryst. Solids, 2007, 353, 1759-1765.

D. Carta, J. C. Knowles, M. E. Smith and R. J. Newport, J. Non. Cryst. Solids, 2007, 353, 11411149.

A. Momeni and M. J. Filiaggi, Acta Biomater., 2016, 41, 328-341. 

and L. F. C. De Oliveira, Mater. Chem. Phys., 2010, 124, 547-551.

21 D. F. Franco, D. Manzani, H. S. Barud, S. G. Antonio, L. F. C. de Oliveira, M. A. P. Silva, S. J. L. Ribeiro and M. Nalin, Rsc Adv., 2016, 6, 91150-91156. Appl., 2014, 28, 1226-1234.

D. F. Franco, H. S. Barud, S. Santagneli, R. S. Lamarca, B. F. Santos, M. A. P. Silva, L. F. C. de Oliveira, S. J. L. Ribeiro and M. Nalin, Mater. Chem. Phys., 2016, 180, 114-121.

A. Momeni and M. J. Filiaggi, Langmuir, 2014, 30, 5256-5266.

A. Momeni, E. M. Valliant, E. P. Brennan-Pierce, J. J. S. Shankar, R. Abraham, P. Colp and M. J. Filiaggi, Acta Biomater., 2016, 32, 286-297.

28 A. Momeni and M. J. Filiaggi, J. Rheol., 2016, 60, 25-34.

F. A. Dias Filho, L. D. Carlos, Y. Messadeq and S. J. L. Ribeiro, Langmuir, 2005, 21, 1776-1783.

31 A. Momeni and M. J. Filiaggi, J. Non. Cryst. Solids, 2013, 382, 11-17.

32 W. Kopp, H. S. Barud, M. F. Paz, L. A. Bueno, R. L. C. C. Giordano and S. J. L. L. Ribeiro, J. Sol-Gel Sci. Technol., 2012, 63, 219-223.

G. Palavit, L. Montagne and R. Delaval, J. Non. Cryst. Solids, 1995, 189, 277-282.

G. Willot, F. Gomez, P. Vast, V. Andries, M. Martines, Y. Messaddeq and M. Poulain, Comptes Rendus Chim., 2002, 5, 899-906.

35 V. Salih, K. Franks, M. James, G. W. Hastings, J. C. Knowles and I. Olsen, J. Mater. Sci. Mater. Med., 2000, 11, 615-620. 
S. P. Valappil, D. M. Pickup, D. L. Carroll, C. K. Hope, J. Pratten, R. J. Newport, M. E. Smith, M. Wilson and J. C. Knowles, Antimicrob. Agents Chemother., 2007, 51, 4453-4461.

I. Ahmed, D. Ready, M. Wilson and J. C. C. Knowles, J. Biomed. Mater. Res. Part A, 2006, 79, $618-626$.

J. M. Casas, M. P. García, M. Sanz, F. Cacho and J. Pérez, Ceram. Int., 2010, 36, 39-46.

40

E. C. de Oliveira Lima, J. M. Moita Neto, F. Y. Fujiwara and F. Galembeck, J. Colloid Interface Sci., 1995, 176, 388-396.

F. Galembeck and E. C. D. Lima, J. Colloid Interface Sci., 1994, 166, 309-315.

D. Priftis, K. Megley, N. Laugel and M. Tirrell, J. Colloid Interface Sci., 2013, 398, 39-50.

C. I. R. De Oliveira, L. F. C. De Oliveira, F. A. Dias Filho, Y. Messaddeq and S. J. L. Ribeiro, Spectrochim. Acta - Part A Mol. Biomol. Spectrosc., 2005, 61, 2023-2028.

L. Popović, D. De Waal and J. C. A. Boeyens, J. Raman Spectrosc., 2005, 36, 2-11.

G. Venkateswara Rao and H. D. Shashikala, J. Adv. Ceram., 2014, 3, 109-116.

A. M. Efimov, J. Non. Cryst. Solids, 1997, 209, 209-226.

Y. M. Moustafa and K. El-Egili, J. Non. Cryst. Solids, 1998, 240, 144-153. Barney, A. C. Hannon, J. C. Knowles and R. J. Newport, J. Non. Cryst. Solids, 2010, 356, 13191324.

51 N. J. Lakhkar, J. H. Park, N. J. Mordan, V. Salih, I. B. Wall, H. W. Kim, S. P. King, J. V. Hanna, R. A. Martin, O. Addison, J. F. W. Mosselmans and J. C. Knowles, Acta Biomater., 2012, 8, 41814190. 
52 T. A. J. Souza, L. P. Franchi, L. R. Rosa, M. A. M. S. da Veiga and C. S. Takahashi, Mutat. Res. Genet. Toxicol. Environ. Mutagen., 2016, 795, 70-83. 